\title{
Elevated level of Galectin-1 in bronchoalveolar lavage of patients with idiopathic pulmonary fibrosis
}

\author{
David Bennett $^{\mathrm{a}, \mathrm{b}, *}$, Elena Bargagli ${ }^{\mathrm{a}, \mathrm{b}}$, Nicola Bianchi ${ }^{\mathrm{a}, \mathrm{b}}$, Claudia Landi ${ }^{\mathrm{a}, \mathrm{b}}$, Antonella Fossi ${ }^{\mathrm{a}, \mathrm{b}}$, \\ Annalisa Fui ${ }^{\mathrm{a}, \mathrm{b}}$, Piersante Sestini ${ }^{\mathrm{a}, \mathrm{b}}$, Rosa Metella Refini ${ }^{\mathrm{a}, \mathrm{b}}$, Paola Rottoli ${ }^{\mathrm{a}, \mathrm{b}}$ \\ ${ }^{a}$ Respiratory Diseases Unit, Department of Medical, Surgical and Neurological Sciences, University of Siena, Italy \\ ${ }^{\mathrm{b}}$ University Hospital of Siena (Azienda Ospedaliera Universitaria Senese, AOUS), Siena, Italy
}

\section{A R T I C L E I N F O}

\section{Keywords:}

Galectin-1

Bronchoalveolar lavage

Idiopathic pulmonary fibrosis

Sarcoidosis

Systemic sclerosis

Biomarker

\begin{abstract}
A B S T R A C T
Rationale: Galectin-1 is a carbohydrate-binding protein involved in apoptosis, cell-proliferation and differentiation, implicated in T-cell homeostasis and survival. The aim of the present study was to determine concentrations of galectin-1 in BAL fluid from patients with IPF and other interstitial lung diseases in order to validate proteomic previous findings.

Methods: 36 IPF patients (16 females, mean age of $64.8 \pm 8.9$ years), 24 sarcoidosis patients (15 females, mean age of $56.3 \pm 13.4$ ), 7 interstitial lung diseases associated to systemic sclerosis (ILD-SSc) patients (5 females, mean age of $55.5 \pm 16.4$ ) and six healthy controls ( 4 females, mean age $47.8 \pm 15.2$ ) were included. Galectin1 concentrations were determined in BAL samples by an ELISA assay.

Results: Galectin-1 concentrations were significantly higher in BAL of IPF patients than in sarcoidosis and ILDSSc patients and healthy controls. In IPF patients, galectin-1 levels showed significant inverse correlations with $\mathrm{DL}_{\mathrm{CO}} \%, \mathrm{~K}_{\mathrm{CO}} \%$ and BAL lymphocyte percentages and a positive correlation with BAL macrophage percentages. Former IPF smokers had higher concentrations of this protein compared with non-smoker IPF patients.

Conclusion: Galectin-1 was confirmed a protein of interest in idiopathic pulmonary fibrosis. Its BAL concentrations were higher in IPF patients than in controls and correlated with disease severity. Galectin-1 was suggested to have a role in the pathogenesis of IPF, principally through the ERK/MAPK pathway and the inhibition of galectin-1 is a potential therapeutic target worthy of research.
\end{abstract}

\section{Introduction}

Galectin-1 is one of the 15 members of a family of widely distributed, highly conserved carbohydrate-binding proteins (lectins) (Gray et al., 2004). They play a crucial role in resolving inflammation through their pro-apoptotic effect on activated leukocytes (Perillo et al., 1995; Rabinovich et al., 2007). However, a pro-inflammatory role of galectin-3 has been demonstrated, suggesting that the effects of galectins depend to the context in which they influence targeted cell (Yamaoka et al., 1995).

Galectin-1 is implicated in many cell functions, including apoptosis and cell turn-over, cell adhesion, immunoregulation, cancer immune evasion, B cell development, mRNA splicing, angiogenesis and nerve and muscle differentiation/homeostasis, principally through the extracellular signal-regulated kinase (ERK) mitogen-activated protein kinase (MAPK) pathway (Cedeno-Laurent and Dimitroff, 2012a).

Increased levels of galectin-1 have been observed in several diseases and it has been linked to progression of many types of cancer, such as osteosarcoma, melanoma, breast, lung and prostate cancer and also to the development of fibrosis of the pancreas and liver, and it greatly accelerates the binding kinetics of HIV-1 to susceptible CD4 cells (Goud et al., 2019a; Maeda et al., 2003a; Wang et al., 2000a).

Some years ago, our research group applied a comparative proteomic analysis to the study of BAL from patients with different interstitial lung diseases (ILD) and from healthy controls demonstrating significant up-regulation of galectin-1 in patients with idiopathic pulmonary fibrosis (IPF) (Magi et al., 2002; Rottoli et al., 2005).

Other members of the galectin family play a role in pulmonary fibrosis. The most widely studied is galectin-3, postulated to have a role in pulmonary fibrosis due to increased concentrations measured in BAL of idiopathic pulmonary fibrosis (IPF) patients and due to its high expression in areas of fibrosis of lung specimens from patients with usual interstitial pneumonia (UIP) (Nishi et al., 2007; Mackinnon et al., 2012). There are ongoing clinical trials into the therapeutic potential of

\footnotetext{
* Corresponding author at: University Hospital of Siena (Azienda Ospedaliera Universitaria Senese, AOUS), Viale Bracci, 16 - 53100 Siena, Italy.

E-mail address: david.btt@gmail.com (D. Bennett).
} 
Table 1

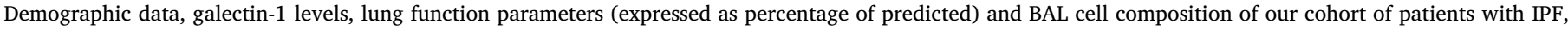

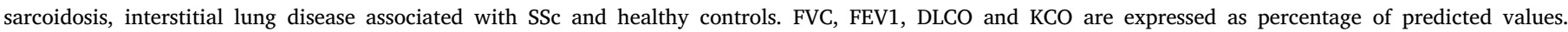

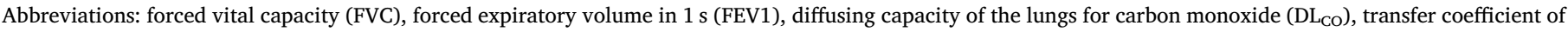
the lung for carbon monoxide ( $\mathrm{K}_{\mathrm{CO}}$ ), BAL lymphocyte CD4/CD8 ratio (RCD4/CD8).

\begin{tabular}{|c|c|c|c|c|c|}
\hline $\mathrm{N}$ & $\begin{array}{l}\text { IPF } \\
36\end{array}$ & $\begin{array}{l}\text { Sarcoidosis } \\
24\end{array}$ & $\begin{array}{l}\text { ILD-SSC } \\
7\end{array}$ & $\begin{array}{l}\text { Controls } \\
6\end{array}$ & $\mathrm{p}$ \\
\hline Sex (females) & $16(44.5 \%)$ & $15(62.2 \%)$ & $5(71.4 \%)$ & $4(66.7 \%)$ & 0.351 \\
\hline Age, years & $64.8 \pm 8.9$ & $56.3 \pm 13.4$ & $55.5 \pm 16.4$ & $47.8 \pm 15.2$ & $<0.001$ \\
\hline Smoking history (ex-smokers and current smokers) & $22(61.1 \%)$ & $9(37.5 \%)$ & $3(42.9 \%)$ & $3(50 \%)$ & 0.330 \\
\hline Packs/year & $28.6 \pm 11.3$ & $17.7 \pm 11.6$ & $16.6 \pm 5.7$ & $11.5 \pm 6.0$ & 0.031 \\
\hline BAL Gal-1/prot-tot. ng/ml & $0.41 \pm 0.24$ & $0.14 \pm 0.13$ & $0.16 \pm 0.09$ & $0.25 \pm 0.11$ & 0.004 \\
\hline \multicolumn{6}{|l|}{ Lung function tests } \\
\hline - $\mathrm{FVC} \%$ & $73.7 \pm 21.2$ & $98.0 \pm 20.3$ & $84.8 \pm 22.6$ & $102.1 \pm 10.5$ & 0.001 \\
\hline - FEV1\% & $76.5 \pm 20.3$ & $92.7 \pm 15.8$ & $78.8 \pm 18.8$ & $97.1 \pm 12.8$ & 0.019 \\
\hline - $\mathrm{FEV} 1 / \mathrm{VC} \%$ & $83.2 \pm 5.6$ & $75.3 \pm 7.2$ & $78.1 \pm 6.4$ & $76.3 \pm 4.1$ & 0.005 \\
\hline - $\mathrm{DL}_{\mathrm{CO}} \%$ & $42.8 \pm 21.2$ & $71.0 \pm 19.1$ & $52.6 \pm 15.7$ & $82.1 \pm 10.9$ & $<0.001$ \\
\hline - $\mathrm{K}_{\mathrm{CO}} \%$ & $67.3 \pm 31.1$ & $87.3 \pm 15.1$ & $72.8 \pm 16.8$ & $99.9 \pm 12.3$ & 0.026 \\
\hline \multicolumn{6}{|l|}{ BAL cellular composition } \\
\hline - Total cells count & $9001111 \pm 5380912$ & $\begin{array}{l}5809230 \pm \\
3739681\end{array}$ & $\begin{array}{l}6300000 \pm \\
2669269\end{array}$ & $\begin{array}{l}8687500 \pm \\
6026659\end{array}$ & 0.148 \\
\hline - Cells/ml of recovered BAL & $\begin{array}{l}175453 \pm \\
143844\end{array}$ & $\begin{array}{l}118477 \pm \\
68740\end{array}$ & $\begin{array}{l}95760 \pm \\
37865\end{array}$ & $\begin{array}{l}155160 \pm \\
90257\end{array}$ & 0.278 \\
\hline - Macrophages & $66.1 \pm 17.6$ & $56.5 \pm 20.4$ & $56.3 \pm 30.6$ & $70.5 \pm 23.2$ & 0.034 \\
\hline - Lymphocytes & $14.5 \pm 11.9$ & $35.6 \pm 22.8$ & $17.3 \pm 10.7$ & $10.8 \pm 6.9$ & 0.001 \\
\hline - Neutrophils & $12.1 \pm 11.0$ & $5.1 \pm 8.4$ & $18.5 \pm 34.2$ & $9.1 \pm 11.7$ & 0.005 \\
\hline - Eosinophils & $7.0 \pm 7.0$ & $2.5 \pm 3.3$ & $7.8 \pm 9.3$ & $0.7 \pm 1.1$ & 0.001 \\
\hline - $\mathrm{RCD} 4 / \mathrm{CD} 8$ & $1.5 \pm 1.3$ & $3.9 \pm 4.1$ & $0.55 \pm 0.44$ & $2.2 \pm 1.7$ & 0.001 \\
\hline
\end{tabular}

inhibiting galectin-3 in IPF patients with a specific galectin-3 inhibitor (TD139) (ClinicalTrials.gov Identifier: NCT02257177, 2019; ClinicalTrials.gov Identifier: NCT03832946, 2019). Galectin-9 is also implicated in the pathogenesis of interstitial lung diseases (Katoh et al., 2015; Matsumoto et al., 2013). Taken together, these findings suggest that galectins are implicated in lung fibrosis etiopathogenesis and their inhibition may be useful in therapeutic management (Kathiriya et al., 2017; Jiang et al., 2019).

The aim of the present study was to determine concentrations of galectin-1 in BAL fluid from patients with different interstitial lung diseases in order to validate proteomic previous findings and to evaluate its clinical utility as a potential biomarker.

\section{Methods}

\subsection{Patients}

Thirty-six IPF patients (16 female, mean age of $64.8 \pm 8.9$ years), twenty-four sarcoidosis patients (15 female, mean age of $56.3 \pm 13.4$ ), seven interstitial lung diseases associated to systemic sclerosis (ILD-SSc) (ILD-SSc) patients ( 5 female, mean age of $55.5 \pm 16.4$ ) and six healthy controls ( 4 female, mean age of $47.8 \pm 15.2$ ) were enrolled in the study. All patients were enrolled and followed-up at the Regional Sarcoidosis and Other Interstitial Lung Diseases Referral Centre in Siena, Italy. All patients were diagnosed according to the latest clinical guidelines (Raghu et al., 2018; Hunninghake et al., 1999; Anon., 1980). They underwent high resolution computed tomography (HRCT) scan of the chest during diagnostic pathway, that were classified by a radiologist experienced in ILDs. Demographic features, medical history, including comorbidities, radiological and functional data were retrospectively collected in an electronical database.

Control subjects had no history of respiratory diseases and were not on therapy of any kind. They had normal lung function parameters. All subjects gave their written informed consent to the study that was approved by Local Ethic Comittee.

\subsection{Bronchoalveolar lavage}

Bronchoalveolar lavage (BAL) was performed for diagnostic and clinical purposes with the informed consent of patients, as previously described (Bargagli et al., 2013). Patients were not on pharmacological therapies at the time of bronchoscopy and BAL. BAL fluid was obtained by instillation of four $60-\mathrm{ml}$ aliquots of saline solution by fibrobronchoscope (Olympus IT-10). The first sample was kept separate from the others and was not used for immunological tests. Cells were separated by centrifuge and the fluid fraction was frozen until enzyme assay. Cell differential counts were performed. Lymphocyte phenotype was analysed by flow cytometry (Facs-Calibur Becton \& Dickinson) using anti-CD3, CD4 and CD8 monoclonal antibodies (Becton \& Dickinson). BAL samples were cultured for microbes, fungi and viruses to exclude infections (Bargagli et al., 2013).

\subsection{Laboratory analysis}

Galectin-1 concentrations were evaluated in BAL samples by a commercially available ELISA assay (USCN Life Science Inc.). The kit is a sandwich enzyme immunoassay for in vitro quantitative measurement of Galectin-1 (GAL1) in human serum, plasma and other biological fluids. Concentrations were reported as Galectin-1/total protein (ng/ $\mathrm{ml}$ ) of recovered BAL fluid.

Total proteins in BAL were determined with a commercial available assay (Sigma-Aldrich, Massachusetts, USA). Samples were processed for a 96-well plate assay protocol using Bradford Reagent for 0.1-1.4 mg/ $\mathrm{ml}$ protein and standard curves were obtained using bovine serum albumin according to the manufacturer's instructions. The samples were incubated for $20 \mathrm{~min}$ and fluorescence was read at $595 \mathrm{~nm}$ with a Perkin Elmer Victor X4 fluorimeter.

\subsection{Statistical analysis}

All data are presented as mean \pm standard deviation $(M \pm S D)$. Non-parametric tests were used to perform statistical analysis (MannWhitney test to compare two groups and Kruskal-Wallis test to compare three or more groups followed by Dunn's test, when significant). Significance was set at $\mathrm{p}<0.05$. Spearman's test was used for correlations between variables. Statistica v 7.0 software was used and graphic representations of data were generated using GraphPad Prism Version 4.0 for Windows. 


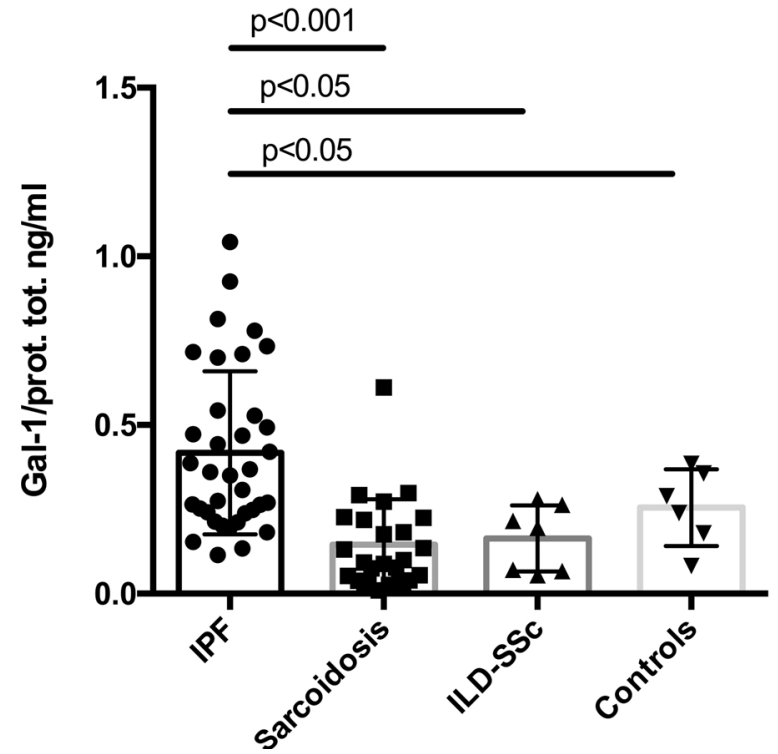

Fig. 1. Galectin-1 concentrations in BAL samples from patients with IPF, sarcoidosis, ILD-SSc and healthy controls.

\section{Results}

Table 1 showed the demographic data, galectin-1 levels, lung function parameters and BAL cell composition of our cohort of patients with IPF, sarcoidosis and ILD-SSc and of healthy controls. IPF patients were found more exposed to tobacco (expressed as both prevalence and pack/year) and had significant lower values of FVC, FEV1, DLCO and KCO and higher values of FEV1/VC respect to others patients' groups and controls. Regarding cellular BAL composition we did not find significant differences in total cells number and number of cells per $\mathrm{ml}$ of BAL fluid recovered; however different cellular profile was observed among groups: in IPF and ILD-SSc patients we observed higher percentage of neutrophils and eosinophils, while in sarcoidosis patients higher lymphocytes percentage was present with increased CD4/CD8 ratio (Table 1).

Galectin-1 concentrations were significantly different in BAL samples from patients with IPF than in patients with ILD-SSc $(\mathrm{p}<0.05)$, sarcoidosis ( $\mathrm{p}<0.01$ ) or healthy controls ( $<<0.01$ ) (Fig. 1). Among IPF patients, former smokers had higher concentrations of galectin1than never smokers ( $\mathrm{p}=0.025)$ (Fig. 2).

In IPF patients, galectin-1 levels showed significant inverse correlations with diffusing capacity of the lungs for carbon monoxide $\left(\mathrm{DL}_{\mathrm{CO}}\right)$ $\%$ of predicted, transfer coefficient of the lung for carbon monoxide $\left(\mathrm{K}_{\mathrm{CO}}\right) \%$ of predicted and BAL lymphocyte percentages, and a positive correlation with BAL macrophage percentages; no correlations with other cellular BAL components, total cells number and number of cells per $\mathrm{ml}$ of BAL fluid recovered nor other functional respiratory parameters were found. Regarding smoking habits, a positive correlation was found between galectin-1 concentrations in BAL and number of packs/year among smokers (patients and controls together, $\mathrm{n}=37$ ) (Table 2).

\section{Discussion}

Galectin- 1 is found in many cells and tissues. It is mainly secreted by activated $\mathrm{T}$ and $\mathrm{B}$ cells and its production is upregulated in activated endothelial cells, macrophages, Treg CD4 + CD25 + cells and NK lymphocytes. It is implicated in diseases such as tumours and fibrosis of the pancreas and liver (Goud et al., 2019a; Maeda et al., 2003a; Wang et al., 2000a).

We aimed to evaluate the role of galectin- 1 in patients with different

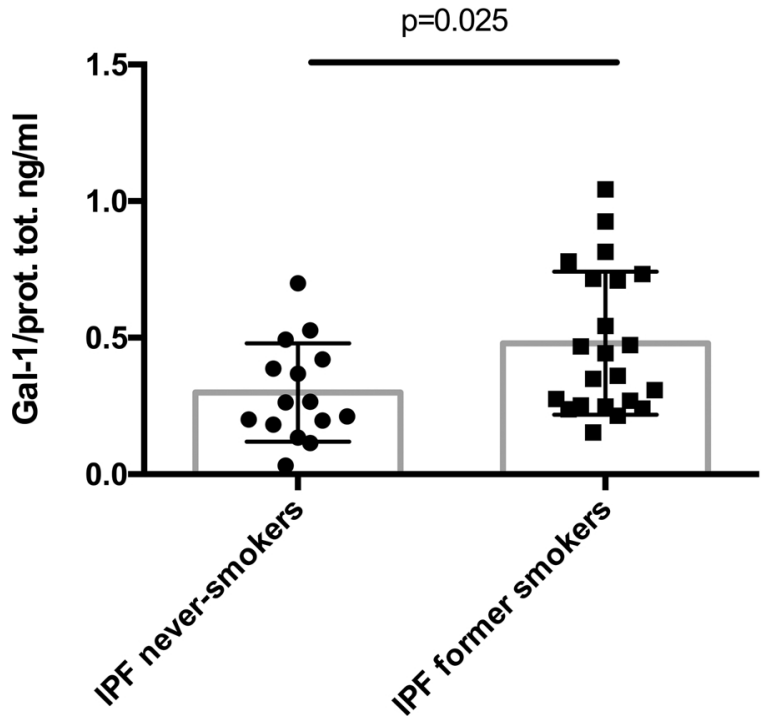

Fig. 2. Galectin-1 concentrations in BAL samples from ex-smoker and nonsmoker IPF patients.

Table 2

Significant correlations between galectin-1 in BAL and demographic data, lung function parameters and BAL data in our entire population and IPF patients. Abbreviations: forced vital capacity (FVC), forced expiratory volume in $1 \mathrm{~s}$ (FEV1), diffusing capacity of the lungs for carbon monoxide $\left(\mathrm{DL}_{\mathrm{CO}}\right)$, transfer coefficient of the lung for carbon monoxide $\left(\mathrm{K}_{\mathrm{CO}}\right)$.

\begin{tabular}{ll}
\hline Variables & Statistics \\
\hline Whole population & $\mathrm{r}=0.37, \mathrm{p}=0.029$ \\
$\bullet$ Packs/year & \\
$\mathrm{IPF}$ & $\mathrm{r}=-0.34, \mathrm{p}=0.040$ \\
$\bullet \mathrm{DL}_{\mathrm{CO} \%} \%$ & $\mathrm{r}=-0.33, \mathrm{p}=0.048$ \\
$\bullet \mathrm{K}_{\mathrm{CO} \%} \%$ & $\mathrm{r}=-0.50, \mathrm{p}=0.011$ \\
$\bullet$ BAL lymphocyte \% & $\mathrm{r}=0.51, \mathrm{p}=0.040$ \\
\hline BAL macrophage \% & \\
\hline
\end{tabular}

interstitial lung diseases, determining its concentrations in BAL of a cohort of patients with IPF, sarcoidosis, ILD-SSc and correlating the results with clinical and lung function data. Our study follows previous observations by our research group firstly reporting galectin-1 differential expression in BAL of patients with different interstitial lung diseases by 2-DE proteomic approach. In that study, galectin-1 was significantly more abundant in BAL from patients with IPF than those with sarcoidosis (\%volume $0.008 \pm 0.008$ in IPF and $0.026 \pm 0.010$ in sarcoidosis, $\mathrm{p}=0.015)$ and ILD-SSc $(\mathrm{p}<0.01)$, suggesting that this protein participates in the pathogenesis of IPF (Magi et al., 2002; Rottoli et al., 2005).

In the present validation study, galectin-1 was confirmed to be higher in BAL of patients with IPF than in patients with sarcoidosis, ILD-SSc and healthy controls. Significantly higher concentrations of galectin-1 were observed in IPF patients than in other patients and no differences were found between patients with sarcoidosis, ILD-SSc and healthy controls. Interestingly, in IPF patients, galectin-1 showed significant inverse correlations with $\mathrm{DL}_{\mathrm{CO}} \%, \mathrm{~K}_{\mathrm{CO}} \%$ and $\mathrm{BAL}$ lymphocyte percentages and a direct correlation with BAL macrophage percentages, suggesting that this protein could be useful as a prognostic biomarker.

Smoking influenced galectin-1 expression. In our IPF cohort, smokers showed the highest concentrations of galectin-1 in BAL. When we analysed our population as a whole, a positive correlation with the number of packs/year was found. Close association between tobacco smoke and galectins production has been observed by others. Nicotine has been shown to induce expression of galectin-3 in breast cancer cell 
lines, primary tumours from breast cancer patients and airway epithelium from COPD patients (Guha et al., 2014; Pouwels et al., 2016).

Galectin-1 has numerous biological functions, which it fulfils through different intracellular pathways. It has also been implicated in fibrotic diseases involving different organs. Galectin- 1 and -3 have both been reported to play a crucial role in chronic fibrotic pancreatitis: galectin-1 is up-regulated in pancreatic fibroblasts (Wang et al., 2000b). Fitzner et al. demonstrated in vitro that activation of rat pancreatic stellate cells, critical for the development of pancreatic fibrosis, is associated with increased expression of galectin-1 (Fitzner et al., 2005). Similar observations have been reported for liver fibrosis, in which galectins 1 and 3 have been shown to activate the MEK1/2-ERK1/2 signalling pathway in hepatic stellate cells (Maeda et al., 2003b).

Galectin-1 naturally stimulates the ERK/MAPK pathway (Paz et al., 2001; Elad-Sfadia et al., 2002). This signalling pathway is overexpressed in idiopathic pulmonary fibrosis, and in particular it is implicated in the fibroblast to myofibroblast transition (Peng et al., 2019; Qu et al., 2019; Antoniou et al., 2010). Interaction of galectin-1 with Ras, and the subsequent activation of the MAPK, ERK and NF-KB pathways, induces overexpression of COX-2 (Chung et al., 2012), which is also implicated in IPF mechanisms. The double homozygosis (GG/CC) at the SNP loci of COX2.3050 and COX2.8473 polymorphisms increases susceptibility to IPF (Xaubet et al., 2010).

Galectin-1 showed to participate to Th1/Th2 imbalance toward Th2 phenotype that commonly predominates in fibrotic diseases. In CD4+ lymphocytes cells, but mainly in CD8 $+\mathrm{T}$ cells, Galectin- 1 acts as a negative regulator of anti-tumor immunity. It demonstrated to selectively induce apoptosis on pro-inflammatory Th1 and Th17 cell subsets, but not on naïve, Th2 or regulatory FoxP3 $+\mathrm{T}$ cells (Cedeno-Laurent and Dimitroff, 2012b; Corapi et al., 2018). It also plays a crucial role on B compartment. Galectin-1 showed to have an important role in the induction of B regulatory cells. Mice deficient of Gal-1 (Gal-1-/-) B cells were unable to suppress TNF- $\alpha$ expression by activated CD4 + T cells (Alhabbab et al., 2018). B regulatory cells have been postulated to participate in long-term graft acceptance mechanisms in lung transplant patients and some abnormalities of B cells have been found in IPF patients with close association with disease manifestations and patient outcomes (Piloni et al., 2019; Xue et al., 2013).

Moreover, Galectin-1 showed activity on macrophage homeostasis. It induces macrophage M2 phenotype, suggesting its potential role in the control of macrophage function during the resolution of inflammation (Abebayehu et al., 2017). It also participates to modulation of inflammation through inducing apoptosis by binding to CD45 + cells (Sasaguri et al., 2017). In IPF lung tissue, the predominant infiltration of M2 macrophages acts as a vital regulator of fibrogenesis. M2 macrophages express high levels of Th2-type cytokines (such as IL-4, IL-13, TGF- $\beta$, and IL-10) and are implicated in the aberrant wound-healing during fibrosis, producing important mediators such as TGF- $\beta$ and PDGF (Zhang et al., 2018).

Using a proteomic approach, galectin-1, in combination with $\boldsymbol{\alpha} 1$ protease inhibitor, is reported to be overexpressed in the early phase of radiation-induced pulmonary fibrosis in a mouse model ( $\mathrm{Im}$ et al., 2006). A profibrotic role of galectin-1 in the lungs has also been proposed by Kathiriya et al. in a mouse model of pulmonary fibrosis acute exacerbations. The authors observed that hypoxia raised expression of phosphorylated FAK1, galectin-1 and $\alpha$-smooth muscle actin and reduced caspase- 3 activation (Kathiriya et al., 2017). In that study, galectin-1 inhibition was shown to induce apoptosis, to reduce FAK1 activation and to attenuate fibrosis-associated lung function decline; interestingly, upregulation of galectin- 1 in the lungs of IPF patients, specifically in hyperplastic regions of fibrotic damage, was also observed (Kathiriya et al., 2017).

Inhibition of galectin-1 has been proposed as a therapeutic mechanism in several conditions. In a mouse model of liver fibrosis, expression levels of galectin-1, TGF- $\beta 1$, CTGF and $\alpha$-SMA were downregulated by silencing gene expression of galectin-1 (Jiang et al., 2019).
Inhibition of galectin-1 has also been proposed as a possible treatment for renal fibrosis in diabetics, for several types of cancer and for HIVinfected cells (Al-Obaidi et al., 2019; Goud et al., 2019b; Chang et al., 2017).

Biomarkers discovery in IPF is a major topic and several molecules, including KL6, Calgranulin B, VEGF and many others, have been proposed in serum and BAL, however no specific biomarker has been internationally recognized in clinical practice yet (Ishii et al., 2018; Bennett et al., 2019; Papp et al., 2015). Galectin-1 appears a new candidate in the vast panorama of biomarkers research that could potentially enhance the accuracy of diagnosis and prognosis, reflecting the severity and thus can aid the evaluation of clinical status of these subjects.

Although there are some limitations of this study, as a relatively low number of patients was recruited from a single clinical center with the absence of a validation cohort, this is the first investigation study evaluating the clinical role of BALF Galectin-1 in IPF subjects. Our results suggest that this protein could be useful as a biomarker of severity and that it would be worthwhile examining its role in the pathogenesis of IPF.

In conclusion, galectin-1 was found overexpressed in BAL of patients with IPF with respect to patients with sarcoidosis, ILD-SSc and healthy controls, confirming our previous findings by proteomics. It proved to correlate with disease severity, evaluated by $\mathrm{DL}_{\mathrm{CO}}$ and $\mathrm{K}_{\mathrm{CO}}$, in IPF patients. Numerous observations suggest that galectin-1 may play a role in the pathogenesis of IPF, principally through the ERK/MAPK pathway. Inhibition of galectin-1 may be a therapeutic option worthy of investigation. Further studies are needed to fully understand the role of galectin- 1 in the pathogenesis of IPF and and its potential clinical usefulness.

\section{References}

Abebayehu, D., Spence, A., Boyan, B.D., Schwartz, Z., Ryan, J.J., McClure, M.J., 2017 Galectin-1 promotes an M2 macrophage response to polydioxanone scaffolds. J. Biomed. Mater. Res. A 105 (9), 2562-2571 Sep.

Alhabbab, R., Blair, P., Smyth, L.A., Ratnasothy, K., Peng, Q., Moreau, A., Lechler, R., Elgueta, R., Lombardi, G., 2018. Galectin-1 is required for the regulatory function of B cells. Sci. Rep. 8 (1), 2725 Feb. 9.

Al-Obaidi, N., Mohan, S., Liang, S., Zhao, Z., Nayak, B.K., Li, B., Sriramarao, P., Habib, S.L., 2019. Galectin-1 is a new fibrosis protein in type 1 and type 2 diabetes. FASEB J. 33 (1), 373-387 Jan.

Anon, 1980. Preliminary criteria for the classification of systemic sclerosis (scleroderma). Subcommittee for scleroderma criteria of the American Rheumatism Association Diagnostic and Therapeutic Criteria Committee. Arthritis Rheum. 23 (5), 581-590 May.

Antoniou, K.M., Margaritopoulos, G.A., Soufla, G., Symvoulakis, E., Vassalou, E., Lymbouridou, R., Samara, K.D., Kappou, D., Spandidos, D.A., Siafakas, N.M., 2010. Expression analysis of Akt and MAPK signaling pathways in lung tissue of patients with idiopathic pulmonary fibrosis (IPF). J. Recept. Signal Transduct. Res. 30 (4), 262-269 Aug.

Bargagli, E., Bennett, D., Maggiorelli, C., Di Sipio, P., Margollicci, M., Bianchi, N., Rottoli, P., 2013. Human chitotriosidase: a sensitive biomarker of sarcoidosis. J. Clin. Immunol. 33 (1), 264-270 Jan.

Bennett, D., Salvini, M., Fui, A., Cillis, G., Cameli, P., Mazzei, M.A., Fossi, A., Refini, R.M., Rottoli, P., 2019. Calgranulin B and KL-6 in Bronchoalveolar lavage of patients with IPF and NSIP. Inflammation 42 (2), 463-470 Apr.

Cedeno-Laurent, F., Dimitroff, C.J., 2012a. Galectin-1 research in T cell immunity: past, present and future. Clin. Immunol. 142 (2), 107-116 Feb.

Cedeno-Laurent, F., Dimitroff, C.J., 2012b. Galectin-1 research in T cell immunity: past, present and future. Clin. Immunol. 142 (2), 107-116 Feb.

Chang, W.A., Tsai, M.J., Kuo, P.L., Hung, J.Y., 2017. Role of galectins in lung cancer. Oncol. Lett. 14 (5), 5077-5084 Nov.

Chung, L.Y., Tang, S.J., Sun, G.H., Chou, T.Y., Yeh, T.S., Yu, S.L., Sun, K.H., 2012. Galectin-1 promotes lung cancer progression and chemoresistance by upregulating p38 MAPK, ERK, and cyclooxygenase-2. Clin. Cancer Res. 18 (15), 4037-4047 Aug. 1. ClinicalTrials.gov Identifier: NCT02257177.

ClinicalTrials.gov Identifier: NCT03832946.

Corapi, E., Carrizo, G., Compagno, D., Laderach, D., 2018. Endogenous Galectin-1 in t lymphocytes regulates anti-prostate cancer immunity. Front. Immunol. (9), 2190 Sep. 26.

Elad-Sfadia, G., Haklai, R., Ballan, E., Gabius, H.J., Kloog, Y., 2002. Galectin-1 augments Ras activation and diverts Ras signals to Raf-1 at the expense of phosphoinositide 3kinase. J. Biol. Chem. 277 (40), 37169-37175 Oct. 4.

Fitzner, B., Walzel, H., Sparmann, G., Emmrich, J., Liebe, S., Jaster, R., 2005. Galectin-1 is 
an inductor of pancreatic stellate cell activation. Cell. Signal. 17 (10), 1240-1247 Oct.

Goud, N.S., Soukya, P.S.L., Ghouse, M., Komal, D., Alvala, R., Alvala, M., 2019a. Human Galectin-1 and its inhibitors: privileged target for cancer and HIV. Mini Rev. Med. Chem Mar. 4.

Goud, N.S., Soukya, P.S.L., Ghouse, M., Komal, D., Alvala, R., Alvala, M., 2019b. Human Galectin- 1 and its inhibitors: privileged target for cancer and HIV. Mini Rev. Med. Chem Mar. 4.

Gray, C.A., Adelson, D.L., Bazer, F.W., Burghardt, R.C., Meeusen, E.N., Spencer, T.E. 2004. Discovery and characterization of an epithelial-specific galectin in the endometrium that forms crystals in the trophectoderm. Proc. Natl. Acad. Sci. U. S. A. 101 (21), 7982-7987 May 25.

Guha, P., Bandyopadhyaya, G., Polumuri, S.K., Chumsri, S., Gade, P., Kalvakolanu, D.V., Ahmed, H., 2014. Nicotine promotes apoptosis resistance of breast cancer cells and enrichment of side population cells with cancer stem cell-like properties via a signaling cascade involving galectin-3, $\alpha 9$ nicotinic acetylcholine receptor and STAT3. Breast Cancer Res. Treat. 145 (1), 5-22 May.

Hunninghake, G.W., Costabel, U., Ando, M., Baughman, R., Cordier, J.F., du Bois, R., Eklund, A., Kitaichi, M., Lynch, J., Rizzato, G., Rose, C., Selroos, O., Semenzato, G., Sharma, O.P., 1999. ATS/ERS/WASOG statement on sarcoidosis. American Thoracic Society/European Respiratory Society/World Association of Sarcoidosis and other Granulomatous Disorders. Sarcoidosis Vasc. Diffuse Lung Dis. 16 (2), 149-173 Sep.

Im, H.S., Kim, H.D., Song, J.Y., Han, Y., Lee, D.Y., Kim, C.W., Yun, Y.S., 2006. Overexpression of alpha1-protease inhibitor and galectin-1 in radiation-induced early phase of pulmonary fibrosis. Cancer Res. Treat. 38 (2), 92-98 Apr.

Ishii, H., Kushima, H., Kinoshita, Y., Fujita, M., Watanabe, K., 2018. The serum KL-6 levels in untreated idiopathic pulmonary fibrosis can naturally decline in association with disease progression. Clin. Respir. J. 12 (9), 2411-2418 Sep.

Jiang, Z.J., Shen, Q.H., Chen, H.Y., Yang, Z., Shuai, M.Q., Zheng, S.S., 2019. Galectin-1 gene silencing inhibits the activation and proliferation but induces the apoptosis of hepatic stellate cells from mice with liver fibrosis. Int. J. Mol. Med. 43 (1), 103-116 Jan.

Kathiriya, J.J., Nakra, N., Nixon, J., Patel, P.S., Vaghasiya, V., Alhassani, A., Tian, Z., Allen-Gipson, D., Davé, V., 2017. Galectin-1 inhibition attenuates profibrotic signaling in hypoxia-induced pulmonary fibrosis. Cell Death Discov. 17010 Apr. 103.

Katoh, S., Ikeda, M., Shimizu, H., Abe, M., Ohue, Y., Mouri, K., Kobashi, Y., Oka, M., 2015. Increased Galectin-9 concentration and number of CD4 + Foxp3high + cells in Bronchoalveolar Lavage fluid of patients with cryptogenic organizing pneumonia. Lung 193 (5), 683-689 Oct.

Mackinnon, A.C., Gibbons, M.A., Farnworth, S.L., Leffler, H., Nilsson, U.J., Delaine, T., Simpson, A.J., Forbes, S.J., Hirani, N., Gauldie, J., Sethi, T., 2012. Regulation of transforming growth factor- $\beta 1$-driven lung fibrosis by galectin-3. Am. J. Respir. Crit. Care Med. 185 (5), 537-546 Mar. 1.

Maeda, N., Kawada, N., Seki, S., Arakawa, T., Ikeda, K., Iwao, H., Okuyama, H., Hirabayashi, J., Kasai, K., Yoshizato, K., 2003a. Stimulation of proliferation of rat hepatic stellate cells by galectin-1 and galectin-3 through different intracellular signaling pathways. J. Biol. Chem. 278 (21), 18938-18944 May 23.

Maeda, N., Kawada, N., Seki, S., Arakawa, T., Ikeda, K., Iwao, H., Okuyama, H., Hirabayashi, J., Kasai, K., Yoshizato, K., 2003b. Stimulation of proliferation of rat hepatic stellate cells by galectin-1 and galectin-3 through different intracellular signaling pathways. J. Biol. Chem. 278 (21), 18938-18944 May 23.

Magi, B., Bini, L., Perari, M.G., Fossi, A., Sanchez, J.C., Hochstrasser, D., Paesano, S. Raggiaschi, R., Santucci, A., Pallini, V., Rottoli, P., 2002. Bronchoalveolar lavage fluid protein composition in patients with sarcoidosis and idiopathic pulmonary fibrosis: a two-dimensional electrophoretic study. Electrophoresis 23 (19), 3434-3444 Sep.

Matsumoto, N., Katoh, S., Yanagi, S., Arimura, Y., Tokojima, M., Ueno, M., Hirashima, M., Nakazato, M., 2013. A possible role of galectin-9 in the pulmonary fibrosis of patients with interstitial pneumonia. Lung 191 (2), 191-198 Apr.

Nishi, Y., Sano, H., Kawashima, T., Okada, T., Kuroda, T., Kikkawa, K., Kawashima, S., Tanabe, M., Goto, T., Matsuzawa, Y., Matsumura, R., Tomioka, H., Liu, F.T., Shirai, K., 2007. Role of galectin-3 in human pulmonary fibrosis. Allergol. Int. 56 (1), 57-65 Mar.

Papp, Á, Bene, Z., Gáspár, I., Nagy Jr, B., Kádár, L., Márialigeti, T., Bánfi, A., Baktai, G., Balla, G., Nagy, B., 2015. Decreased VEGF level is associated with elevated ferritin concentration in Bronchoalveolar Lavage Fluid of children with interstitial lung diseases. Respiration 90 (6), 443-450.

Paz, A., Haklai, R., Elad-Sfadia, G., Ballan, E., Kloog, Y., 2001. Galectin-1 binds oncogenic $\mathrm{H}$-Ras to mediate Ras membrane anchorage and cell transformation. Oncogene 20 (51), 7486-7493 Nov. 8.

Peng, X., Li, X., Li, C., Yue, S., Huang, Y., Huang, P., Cheng, H., Zhou, Y., Tang, Y., Liu, W., Feng, D., Luo, Z., 2019. NMDA receptor activation inhibits the protective effect of BM-MSCs on bleomycin-induced lung epithelial cell damage by inhibiting ERK signaling and the paracrine factor HGF. Int. J. Mol. Med. 44 (1), 227-239 Jul.

Perillo, N.L., Pace, K.E., Seilhamer, J.J., Baum, L.G., 1995. Apoptosis of T cells mediated by galectin-1. Nature 378 (6558), 736-739 Dec. 14.

Piloni, D., Morosini, M., Magni, S., Balderacchi, A., Inghilleri, S., Cova, E., Oggionni, T., Frangipane, V., Pandolfi, L., Scudeller, L., Meloni, F., 2019. Peripheral CD19+ CD24(high)CD38(high) B-regulatory cells in lung transplant recipients. Transpl. Immunol. 101245 Sep. 14.

Pouwels, S.D., Hesse, L., Faiz, A., Lubbers, J., Bodha, P.K., Ten Hacken, N.H., van Oosterhout, A.J., Nawijn, M.C., Heijink, I.H., 2016. Susceptibility for cigarette smoke-induced DAMP release and DAMP-induced inflammation in COPD. Am. J. Physiol. Lung Cell Mol. Physiol. 311 (5), L881-L892 Nov. 1.

Qu, H., Liu, L., Liu, Z., Oin, H., Liao, Z., Xia, P., Yang, Y., Li, B., Gao, F., Cai, J., 2019. Blocking TBK1 alleviated radiation-induced pulmonary fibrosis and epithelial-mesenchymal transition through Akt-Erk inactivation. Exp. Mol. Med. 51 (4), 42 Apr. 15.

Rabinovich, G.A., Liu, F.T., Hirashima, M., Anderson, A., 2007. An emerging role for galectins in tuning the immune response: lessons from experimental models of inflammatory disease, autoimmunity and cancer. Scand. J. Immunol. 66 (2-3), 143-158 Aug.-Sep.

Raghu, G., Remy-Jardin, M., Myers, J.L., Richeldi, L., Ryerson, C.J., Lederer, D.J., Behr, J., Cottin, V., Danoff, S.K., Morell, F., Flaherty, K.R., Wells, A., Martinez, F.J., Azuma, A., Bice, T.J., Bouros, D., Brown, K.K., Collard, H.R., Duggal, A., Galvin, L., Inoue, Y., Jenkins, R.G., Johkoh, T., Kazerooni, E.A., Kitaichi, M., Knight, S.L., Mansour, G., Nicholson, A.G., Pipavath, S.N.J., Buendía-Roldán, I., Selman, M., Travis, W.D., Walsh, S., Wilson, K.C., American Thoracic Society, European Respiratory Society, Japanese Respiratory Society, Latin American Thoracic Society, 2018. Diagnosis of idiopathic pulmonary fibrosis. An official ATS/ERS/JRS/ALAT clinical practice guideline. Am. J. Respir. Crit. Care Med. 198 (5), e44-e68 Sep. 1.

Rottoli, P., Magi, B., Perari, M.G., Liberatori, S., Nikiforakis, N., Bargagli, E., Cianti, R., Bini, L., Pallini, V., 2005. Cytokine profile and proteome analysis in bronchoalveolar lavage of patients with sarcoidosis, pulmonary fibrosis associated with systemic sclerosis and idiopathic pulmonary fibrosis. Proteomics 5 (5), 1423-1430 April, PubMed PMID: 15761959.

Sasaguri, K., Yamada, K., Narimatsu, Y., Oonuki, M., Oishi, A., Koda, K., Kubo, K.Y., Yamamoto, T., Kadoya, T., 2017. Stress-induced galectin-1 influences immune tolerance in the spleen and thymus by modulating CD45 immunoreactive lymphocytes. J. Physiol. Sci. 67 (4), 489-496 Jul.

Wang, L., Friess, H., Zhu, Z., Frigeri, L., Zimmermann, A., Korc, M., Berberat, P.O., Büchler, M.W., 2000a. Galectin-1 and galectin-3 in chronic pancreatitis. Lab. Invest. 80 (8), 1233-1241 Aug.

Wang, L., Friess, H., Zhu, Z., Frigeri, L., Zimmermann, A., Korc, M., Berberat, P.O., Büchler, M.W., 2000b. Galectin-1 and galectin-3 in chronic pancreatitis. Lab. Invest. 80 (8), 1233-1241 Aug.

Xaubet, A., Fu, W.J., Li, M., Serrano-Mollar, A., Ancochea, J., Molina-Molina, M., Rodriguez-Becerra, E., Morell, F., Rodríguez-Arias, J.M., Pereda, J., Casanova, A., Molins, L., Picado, C., 2010. A haplotype of cyclooxygenase-2 gene is associated with idiopathic pulmonary fibrosis. Sarcoidosis Vasc. Diffuse Lung Dis. 27 (2), 121-130 Jul.

Xue, J., Kass, D.J., Bon, J., Vuga, L., Tan, J., Csizmadia, E., Otterbein, L., Soejima, M., Levesque, M.C., Gibson, K.F., Kaminski, N., Pilewski, J.M., Donahoe, M., Sciurba, F.C., Duncan, S.R., 2013. Plasma B lymphocyte stimulator and B cell differentiation in idiopathic pulmonary fibrosis patients. J. Immunol. 191 (5), 2089-2095 Sep. 1.

Yamaoka, A., Kuwabara, I., Frigeri, L.G., Liu, F.T., 1995. A human lectin, galectin-3 (epsilon bp/Mac-2), stimulates superoxide production by neutrophils. J. Immunol 154 (7), 3479-3487 Apr. 1.

Zhang, L., Wang, Y., Wu, G., Xiong, W., Gu, W., Wang, C.Y., 2018. Macrophages: friend or foe in idiopathic pulmonary fibrosis? Respir. Res. 19 (1), 170 Sep. 6. 